\title{
POPULAR PARTICIPATION AND SUSTAINABLE DEVELOPMENT DIRECTIVES OF INFORMAL SETTLEMENTS
}

\section{Aymen Eissa Abd-El Alim and Khaled Nasser Barashed}

(Received August 12, 2007 Accepted March 3, 2008)

"In Egypt urban sprawl was early affected by industrialization trend that began in the last century. In the 1960 's, sprawl accelerated as a result of socialistic and industrialization orientation. That resulted in, high urban population density, huge shortage of urban housing, increase of city areas and less increase of city numbers. Many substandard districts grown up. During the 1970's, specific conditions happened such as open economic policy and petroleum employment. Under these circumstances, substandard areas got a new trend to have huge mass and growing velocity. Increased urban population made its efforts to achieve shelter. People built more than 2 million units (4 millions in another estimation) without formal registration. Those units are used to be called Informal Housing. Informal settlements have serious problems related to planning, urban tissue, services, and absence of buildings finishing which give impression of collapsing and city deterioration. In spite of being serious problems and deterioration features there are positive indications. An important Argument appears since inhabitants have low income but they could achieve access to infrastructure, establishment of facilities, and some times- planning roles better than formal areas. That argument establish hypothesis of being special properties and embedded capabilities and power. The study contrives main embedded forces in informal housing and tries to make use of them in future housing projects. The main contrived elements are, detracting factors, attracting factors such as access with work locations, access with exist cities, establishment of critical limit of infrastructure, simple methods of land distribution, embedded economic resources, informal saving types, sustainable and self finance of buildings, and popular participation. Study concludes Sites and Services as suitable method for housing low income groups. Sites and Services method must be adapted by effectuate contrived elements."

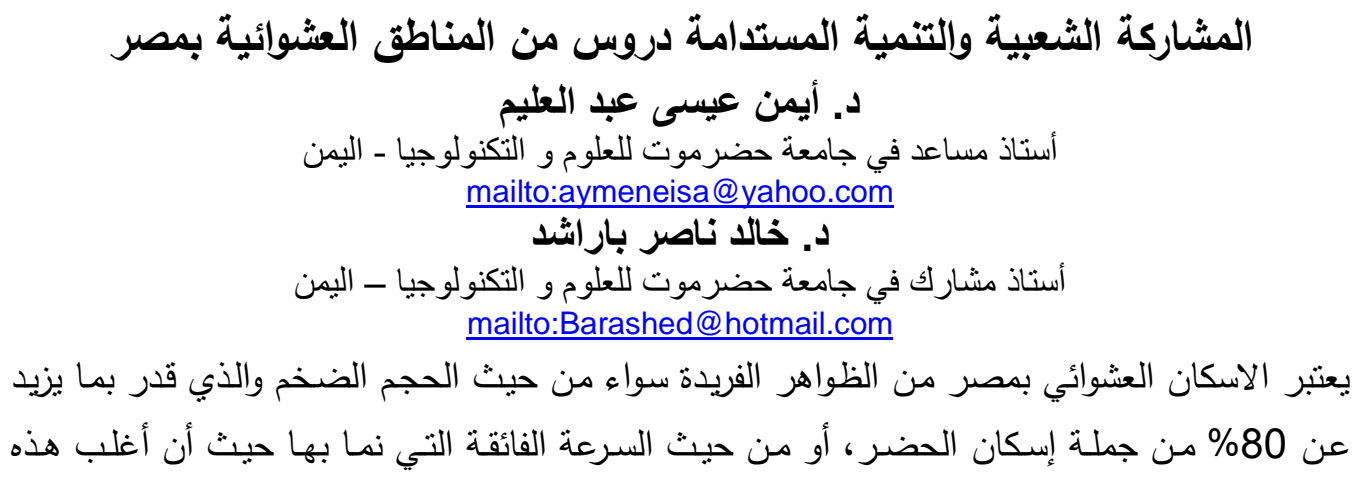


المستقرات نمت في غضون عقد واحد من الزمن، أو من حيث القيمة الاقتصادية بما تتكله تلك الأصول

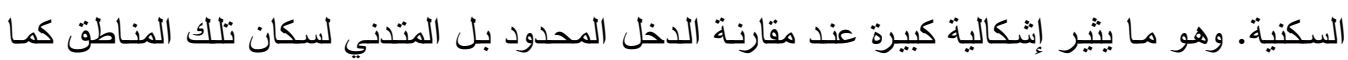
تشير أغلب الدراسات وبين ما تحقق من إسكان يغلب عليه نمط الملكية الخاصة وتزيد هذه الإثكالية في

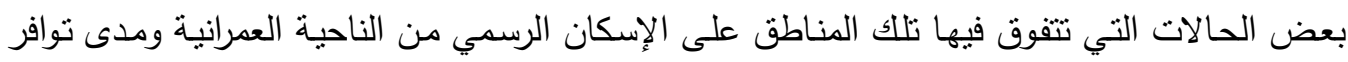

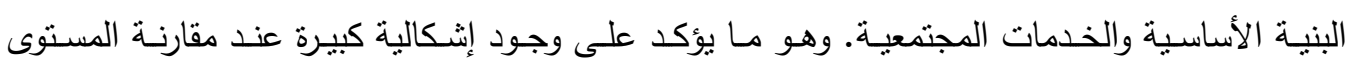

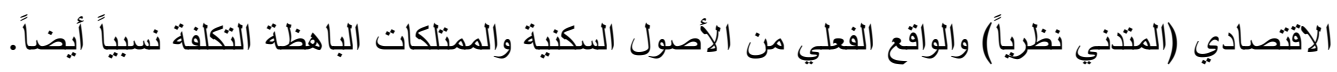

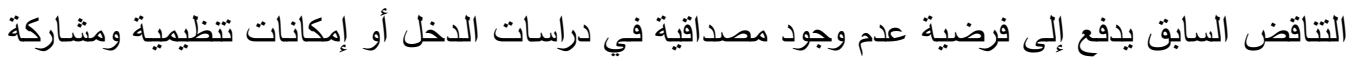

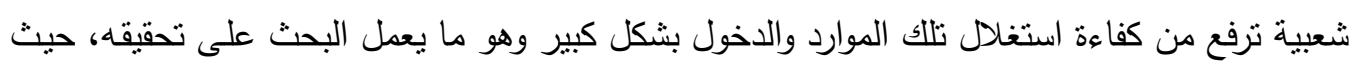

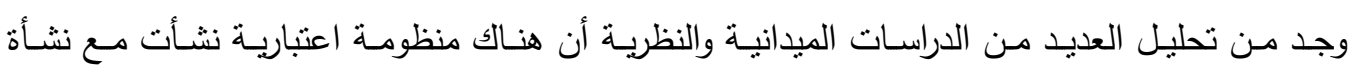

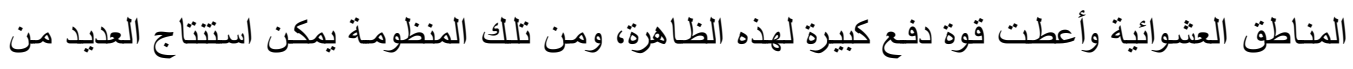

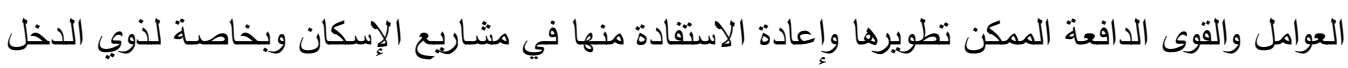

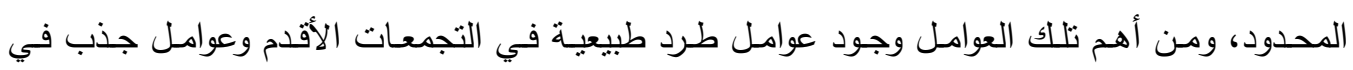

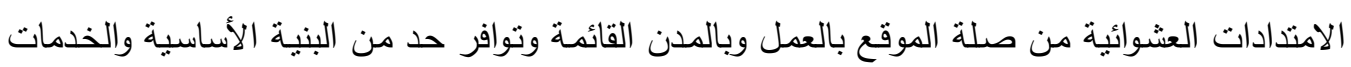

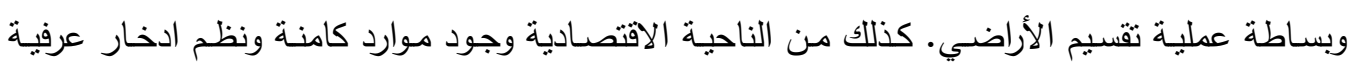
وكذلك نوع من التمويل الذات للبناء ونظم للتقسيط بما يعظم الإمكانات المحدودة. كما تلعب الششاركة الثعبية دوراً كبيراً التتمية العقارية والمجتمعية على السواء.

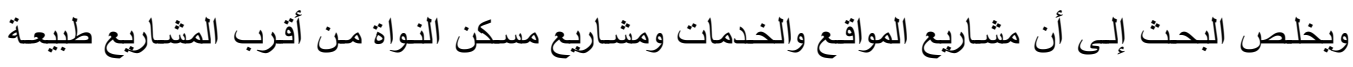
لمنظومة الإسكان العشوائي مما يستوجب إعادة تطوير وتطويع تلك المشاريع للعوامل المستتبطة مثل

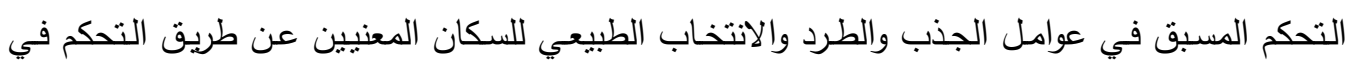

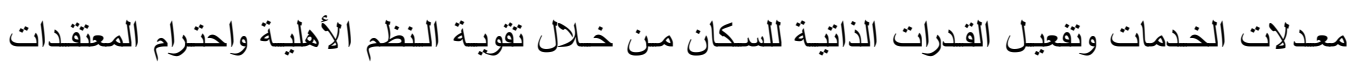
والقناعات وتفعيل الثراكة بما يسرع التتمية.

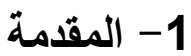

نشـأت المستقرات العشوائية بحجم كبير وسرعة فائقة فاقت كل محاولات الإسكان الحكومي والتتميـة

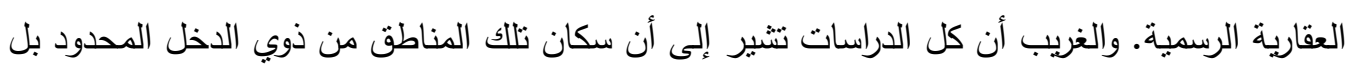

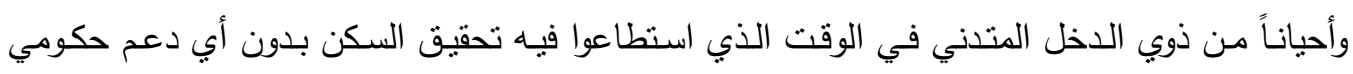

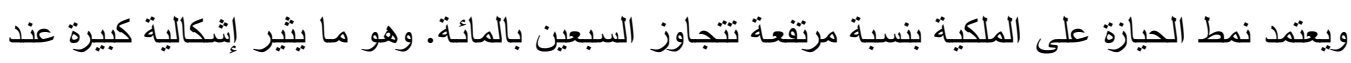

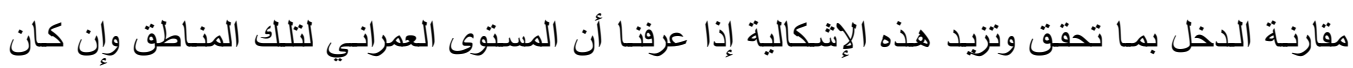
متدني بصورة عامـة إلا أنه يكون في بعض هذه الأحيان بمسنتوى يوازي الإسكان الرسمي بل وفي أحيان 
أخرى وإن كانت نادرة تفوق بعض معايير الإسكان العشوائي الإسكان الرسمي. وكذلك أيضاً بالنسبة التوفير البنية الأساسية والخدمات المجتمعية.

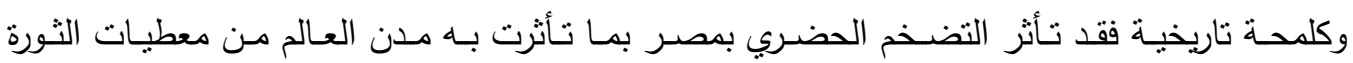

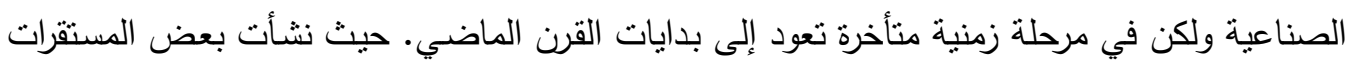

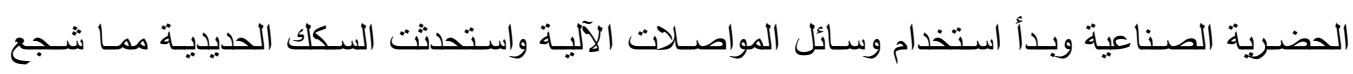

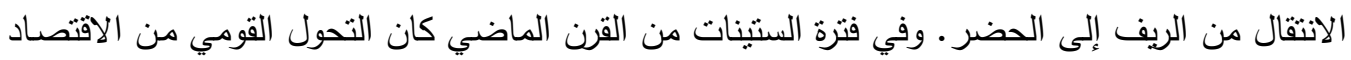

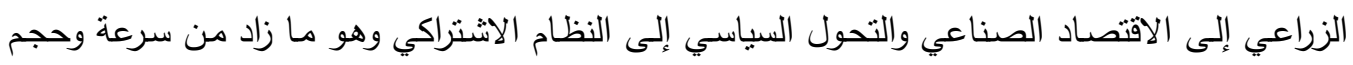

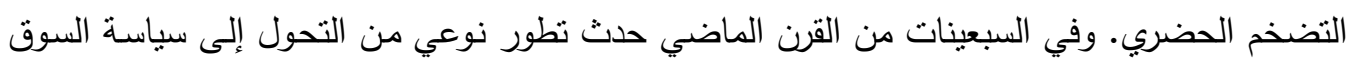

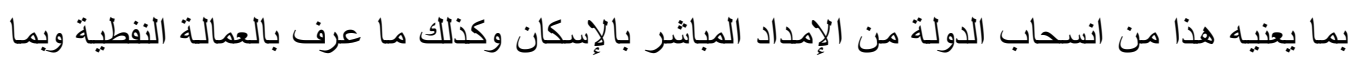

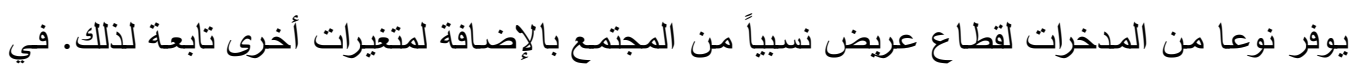

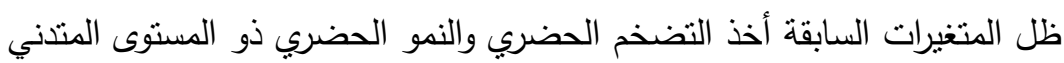

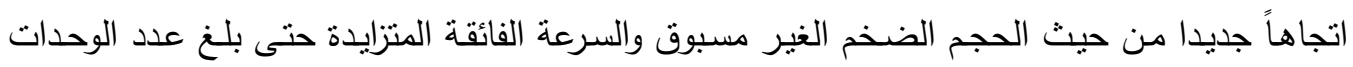

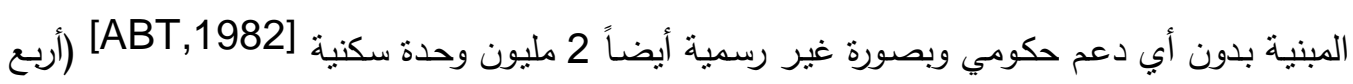

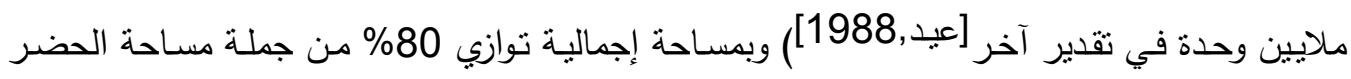
بمصر وفيما عرف بالإسكان العشوائي. وقد تباين توصيف الباحثين لهذه الظاهرة ما بين من يراها سرطان يجب الإنب استئصاله إلى من براها إسكان

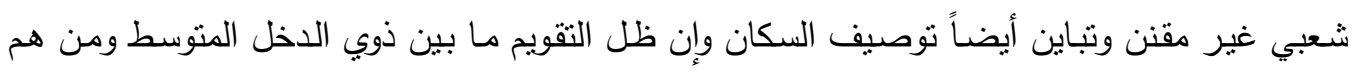
دون ذلك.

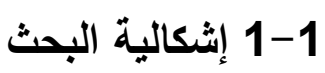

عند مقارنة المستوى الاقتصادي (المتندي نظرياً) من ناحية والواقع الفعلي من تحقيق منطلب أساسي هو

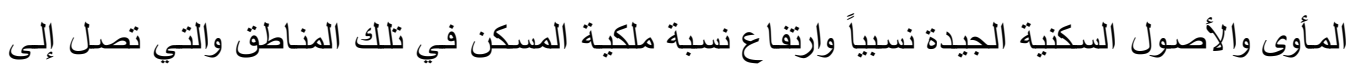
70 [السفطي,1986] والممنكات الباهظة التكلفة نسبياً أيضاً من الناحية الأخرى هنا تبرز إثكالية واضحة تدفع إلى البحث عن فرضيات حلها وعن إمكانية الاستفادة من ذلك.

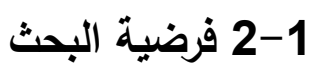

التتاقض السابق يفع إلى فرضية عدم وجود مصداقية في دراسات اللخل وهو ما لا يمكن الاعتماد عليه برجة مقولة نظراً

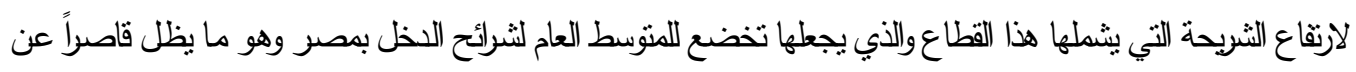

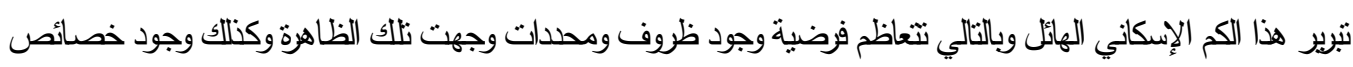
وإمكانات نتظيمية تزفع من كفاءة استغلال تلك الموارد بشكل كيبر وهو ما يعمل البحث على تحقيقة. 
1-3 هذف البحث

يروي البحث إلى استنتاج النمط والمحلدات النتظيية وطيعة اللور المجتمي الذي رفع من كفاءة علية التتمية العرانية بالمناطق العثوائية ومحاولة استثمارها في عطليات النتمية بصورة عامة والنتية العمرانية بصورة خاصة.

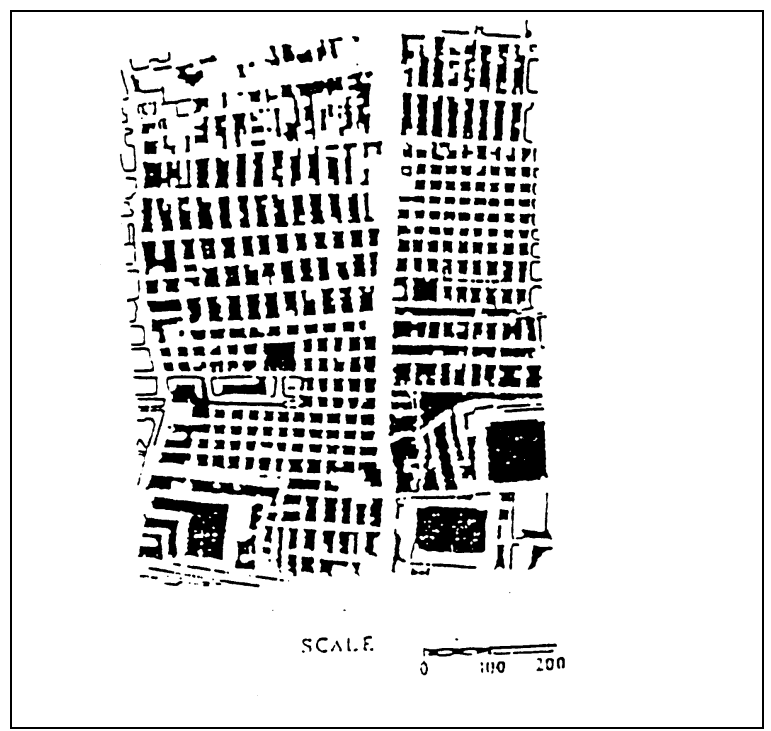

شكل (2) يوضح بلوك المنطقة العشوائية بعزبة عثـان حيث يظهر أسلوب التخطبط وتقسيم الأراضي بصورة شطرنجية] [ABT,1982]

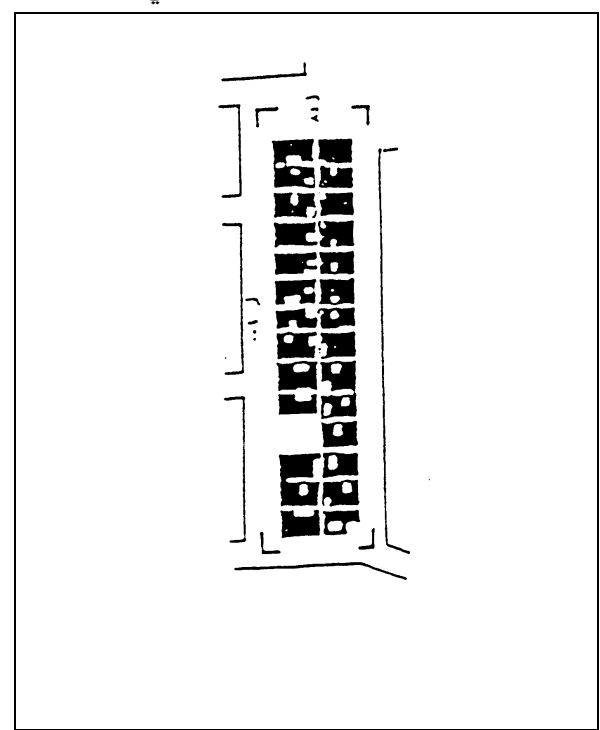

شـكل (1) يوضـح بلـوك سكني بالمنطقة

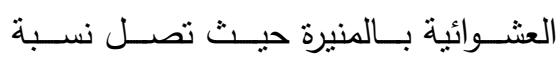

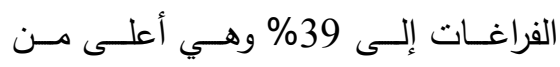
المعدلات الرسمية[سعيد,1986].

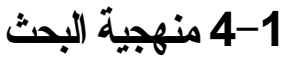

لتحقيق الهف السابق اعتد البحث على العبد من الدراسات النظرية والميدانية التي أجريت في ملينة أسيوط وشملت المسح المياني اللعبد من المناطق العشوائية [عيد,1988]، [الباحث]، [الطلاب,1992] [عبد الحفيظ, 2001] وفي مدينتي القاهزة وبني سويف]ABT, 1982] واعتد على التحليل والتحليل الهقارن والأستقراء. ونظراً لأن الهحف الأساسي من البحث لبس درالسة ظاهرة النمو العثوائي في حد ذاته لذا سوف نعدد إلى تحليل نلك الظاهرة بصورة مختصرة ثم إلى اسنتاج المحدات التي يمكن أن نساعد في برامج نوفير المسكن عن طريق تحليل الآليات المختلفة التي ساهدت في إيجاد ونمو

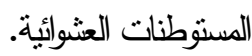

جدول (1) يبين المناطق العشوائية بمدينة أسيوط حسب ظهورها ومساحتها وتعداد كلاً منها سنوات 96 ، 2000 [عبد الحفيظ,2001] 


\begin{tabular}{|c|c|c|c|c|c|c|}
\hline سكان العشوائيات النئية إلى & |السكان2000 & تعداد 96 & المساحة الكلبة إلى & بالفدان & سنة ظهورها & المنطقة \\
\hline$\% 35.76$ & 81600 & 60387 & $\% 45.2$ & 370 & 1950 & الوليدية \\
\hline$\% 20.71$ & 47272 & 37254 & $\% 31.8$ & 260 & 1965 & الحمراء \\
\hline$\% 2.2$ & 500 & 3793 & $\% 1.8$ & 13.5 & 1965 & المدابغ \\
\hline$\% 7.36$ & 16800 & 9034 & $\% 4.9$ & 40 & 1960 & البيسرى \\
\hline \%13.8 & 31500 & - & $\% 9.2$ & 75 & 1960 & السادات \\
\hline$\% 10.08$ & 23000 & - & $\% 6.1$ & 50 & 1950 & جسر السلطان \\
\hline$\% 10.08$ & 23000 & - & $\% 1.2$ & 10 & 1950 & جنينة \\
\hline$\% 100$ & 228172 & & & & & جملة \\
\hline
\end{tabular}

2- نشأة المستوطنات العشوائية:

1-2 آليات نشأة المستوطنات العثوائية:

نشأت المسنوطنات العشوائية متأثرة بعوامل متعددة يمكن تصنيفها إلى عوامل طرد وعوامل جذب في

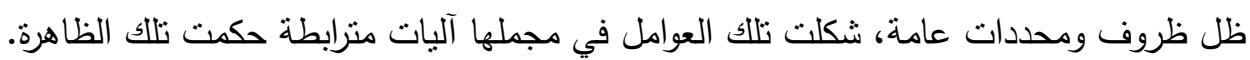
أولاً عوامل الطرد وتتمثل في 1) الزيادة المطردة في عدد سكان الحضر وتكفي الإثـارة إلى أن سكان الحضر بمصر زاد في الفترة من سنة 1960 وحتى سنة 1986 من عشرة ملايين نسمة إلى حوالي الئي

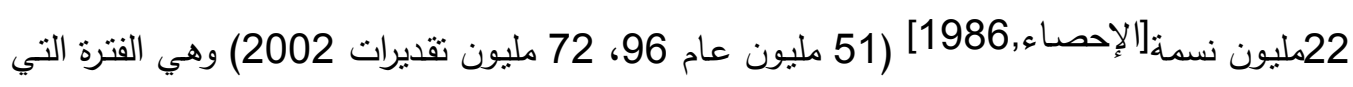
تركز فيها نمو المناط العشوائية. 2) التضخم الحضري في الوقت الذي زاد فيه سكان الحضر بنسبة

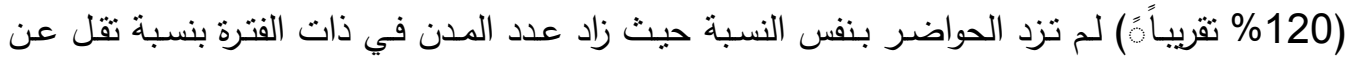

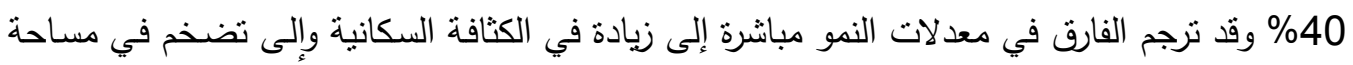
الحواضر القائمة في أغلب الأحوال بدون أب تخطيط مسبق أو تخطيط لا يواكب الزيادة الفعلية. 3)

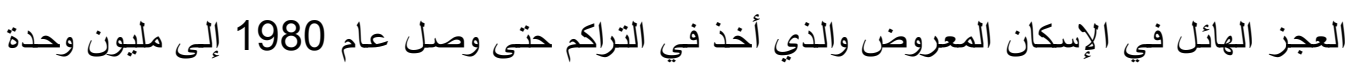

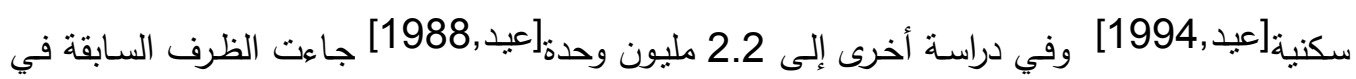


ظل تحولات سياسية واقتصادية من النظام الاشتراكي إلى النظام الغربي ونظام السوق وفي ظل متغيرات

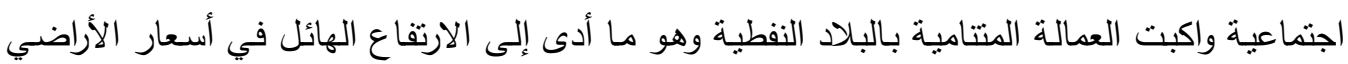
داخل المدن وسبطرة كبار المستثمرين على السوق العقاري بمراكز المدن ووجود مدخرات لدى شريحة الارنه عريضة من المواطنين ولكن لا تفي بالحصول على مسكن داخل المدينة وهو ما دفع إلى البحث عن المأوى بأطراف المدن والقرى القريبة من الحضر وقد حددت مجموعة من العوامل قدرة منطقة عن أخرى

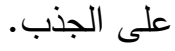

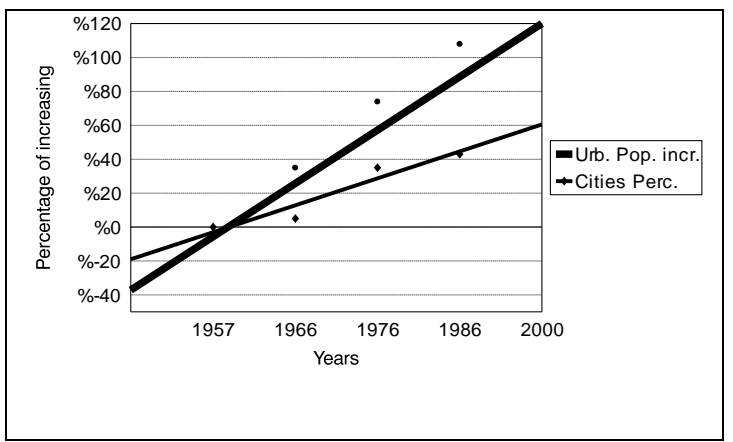

شكل (3) يوضح التباين بين معدلات الزيادة في عدد السكان وعدد الحواضر بمصر بين عامي 1966-

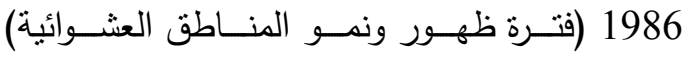

\section{[الإحصاء,1986+|الباحث]}

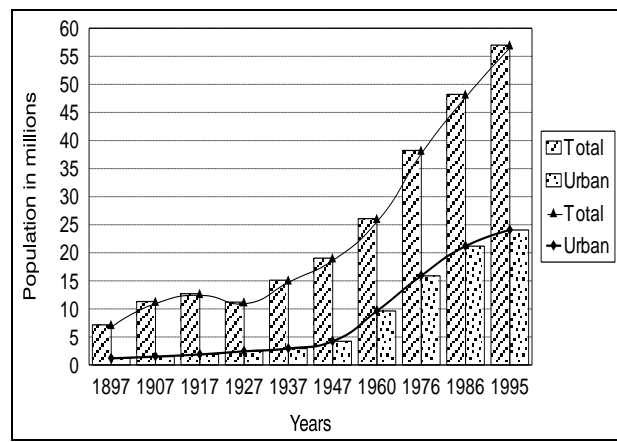

شـكل (2) يوضـح نمـو تعـداد السكان بعموم مصر ونمو تعداد الحضر في الفترة 18971995 [الإحصاء,1986+الباحث] نعرد

ثانياً عوامل الجذب من تحليل العديد من نماذج المستوطنات العشوائية أن من أهم العوامل التي تحدد

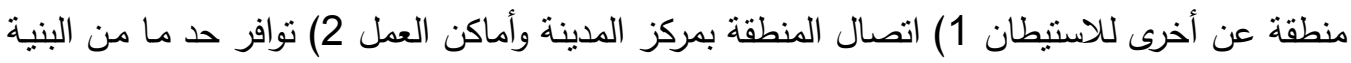
الأساسية حيث وجد أنه إذا زادت نسبة توفر عناصر البنية الأساسية كلما زاد معدل نمو المنطقة ولكن

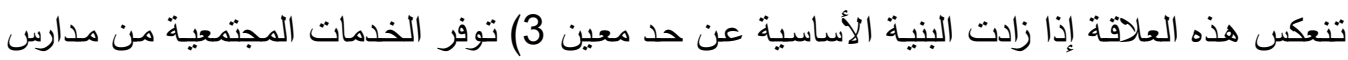
ومتاجر ومساجد [Abdelalim,1994] [إسماعيل,1988]. مما سبق يتضح أن ظهور تلك المستوطنات حدث تحت عوامل من الطرد بالمدن القائمة وجهت السكان

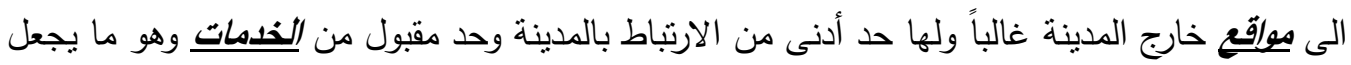
تللك الظاهرة أقرب الى كونها نوع ذاتي غير مرشد من مشاريع المواقع والخدمات. 


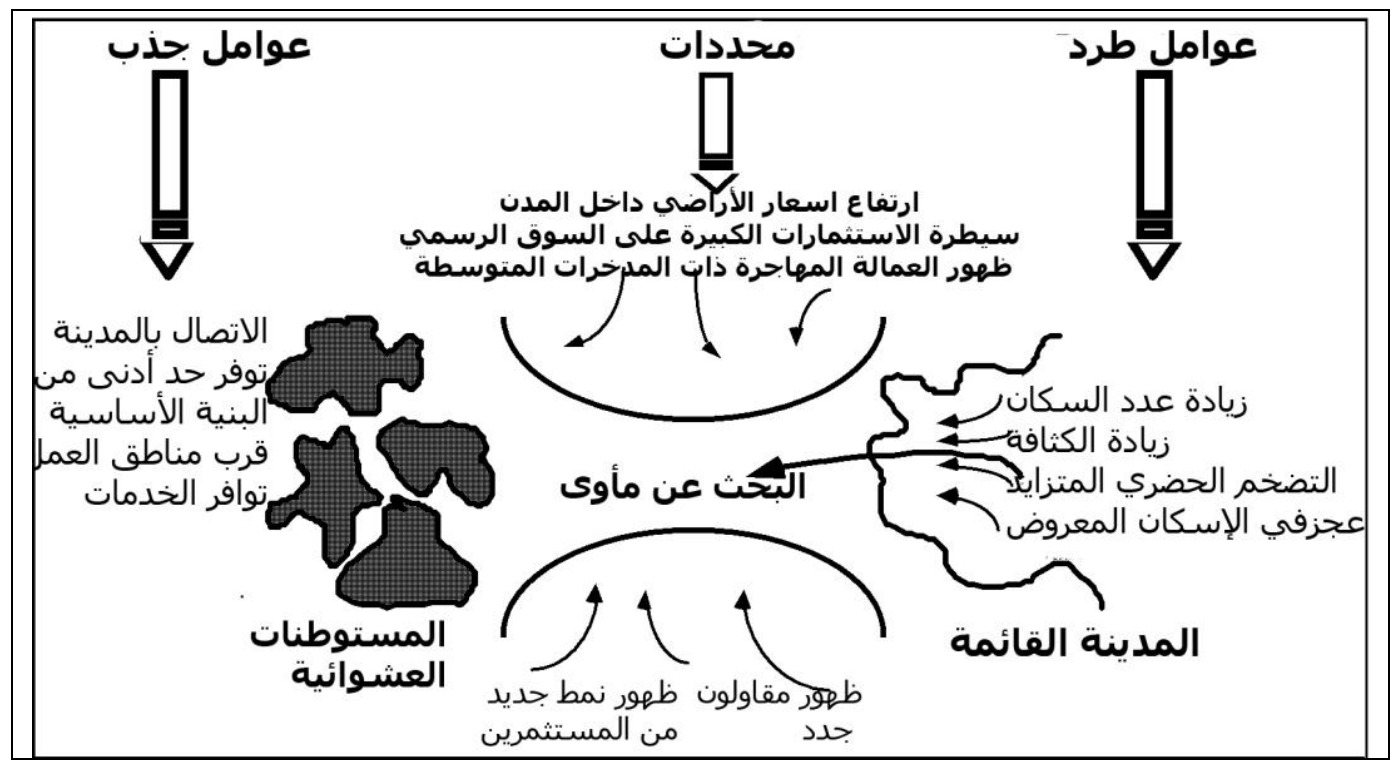

شكل (4) يوضح الآليات التي وجهت وتحكمت في النمو العشوائي[Abdelalim,1994].

\section{2-2 الخبرات المستفادة من آليات النمو العشوائي}

ويمكن من الآليات السابقة استتناج مجموعة من العوامل التي يمكن أن تساعد في توجيه وتحفيز التتمية

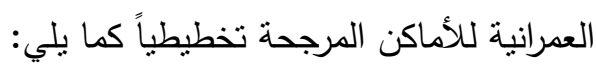

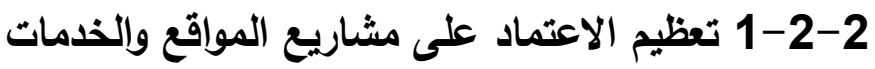

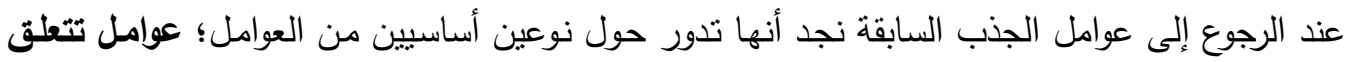
بالموقع (متل العلاقة بين الموقع والعمل - العلاقة بالمدن القائمة - شرايين الحركة الرئيسية...)

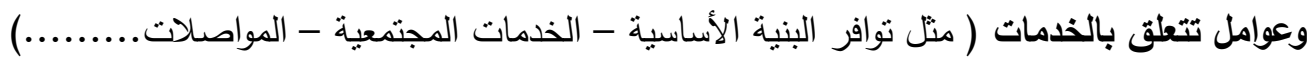
وهو ما يجعل النمو العشوائي صورة تلقائية من مشاريع المواقع والخدمات وهو أحد مبررات الأنية النمو المتزايد

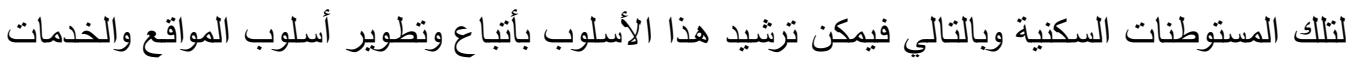
واعتماده كأحد الأساليب الأساسية للإمداد بالإسكان.

2-2-2 التحكم في مستوى الخدمات كانتخاب طبيعي للسكان المعنيين توفير حد مدروس من البنية الأساسية والخدمات المجتمعية وبما يشكل تحديد واختيار طبيعي لثرائح السكان المستهدفين بكل منطقـة. حيث وجد مـن الدراسـات الميدانيـة لبعض المستوطنات العشـوائية بأسيوط [عيد,1988] والقـاهرة وبنـي سـويف[ABT,1982] أن هنـاك نقطـة حرجـة لمستوى الخدمات بالموقع والني عندها يشكل الموقع جذباً لمنوسطي الدخل ودونها يفقد الموقع جاذبيته وقدرته على التتمية، كما أن الارتفاع عن هذا الحد الحرج يبطئ من النمو ويجعل السكان الأعلى دخلاً هم المعنيين بالموقع. 


\section{2-2-2 2-3 الحوافز السلبية}

وهي نللك العوامل التي ندفع السكان بعيداً عن المناطق المرغوب في الحد من نموها ويمكن أن نستخلص منها التالي: وهي الزيادة المحسوبة في الكثافة البنائية والسكانية وبما لا يعطي المدن المراد الحد من نموها أي أفضلية على المناطق المخططة للجذب. النتديد على الاشتراطات البنائية بما يرفع تكلفة البناء

الحد من نركيز الخدمات بتلك المناطق الحد من فرص العمل من تركيز

2-2-2 الحوافز الإيجابية

• توفير اتصال قوي بين المناطق المؤهلة للتتمية ومراكز الددن القريبة. توفير اتصال قوي وغير مكلف بين الدناطق الجديدة وأماكن العمل بالمدن القائمة

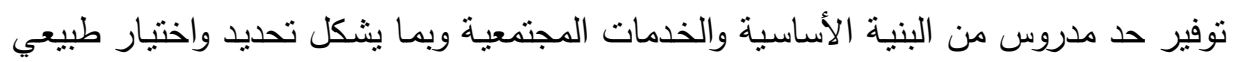

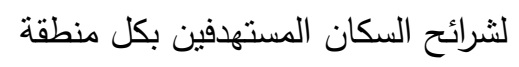

\section{3- التنمية العمرانية}

المراد هنا بتعبير التمية العمرانية هو النشاط التخطيطي والإداري المبذول لتهيئة قطعة أو موقع ما من الأرض لعملية الاستيطان بداية من كونـه مساحة مدمجة وحتى الوصول بـه الى شوارع وقطع محددة الاستخدام جاهزة للتملك والبناء عليها.

\section{3-1-3 نمط التنمية العمرانية بالمناطق العثوائية:}

عند الرجوع إلى تجربة النمو العشوائي نجد أن أسلوب النعامل مع المناطق الجديدة التسم بالبساطة على التى أكثر من صعيد، حيث يقوم المالك الأصلي للأرض والذي غالباً ما يكون أحد الفلاحين أو الفلاحين الذين تحولوا للعمل في الدقاولات يقوم بتقسيم الأرض في صورة شطرنجية متتبع الحدود الحقلية القديمة مع ترك مسافة من أحد الجوانب لكل القطع وكذلك القطع المقابلة لها ليشكل بذلك الثارع هذه الطريقة البسيطة أدت لسرعة تتفيذ التقسيم وكذلك توفير القيم المرتفعة لأتعاب الاستشـاريين وتوجيه هذا الوفر

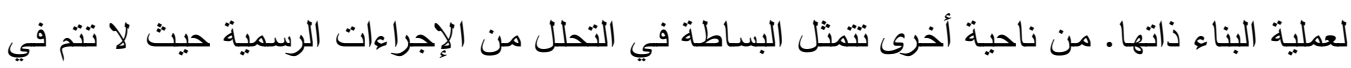

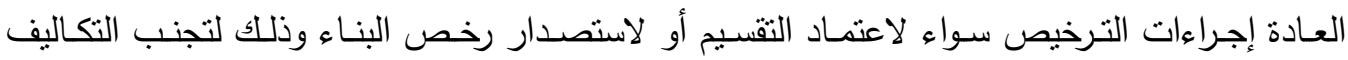
الباهظة نسبيا وخوفاً من الفترة الزمنية التي يحتاجها استصدار الرخصة وبالتالي كان المشتري لقطعة من التصن الأرض يشرع مباشرة في عملية البناء. ومن صور التبسيط الأخرى بساطة أثبات الملكية حيث لانية ينت 
اللجوء في العادة إلى التسجيل في الثشهر العقاري ولكن تبرم عقود عرفية أو بما يعرف بقضايا إثبات صحة التعاقد [القاضي,1986] [إسماعيل,1988].

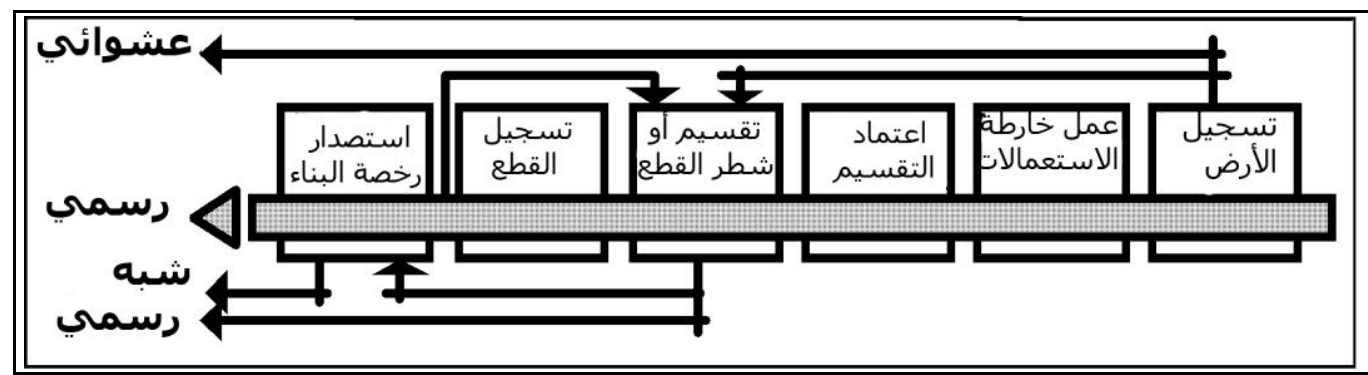

شكل (5) يوضح مراحل استصدار تراخيص البناء ومراحل تجاوزها كلياً أو جزئياً [عيد,1988].

3-2-3 الخبرات المستفادة:

يمكن مما سبق استتناج بعض عناصر التبسيط الني تساعد على سرعة نمو المشاريع السكنية وخاصة

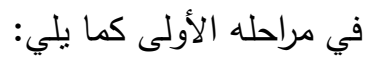
3-2-3 بساطة التقسيم

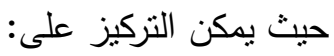
• بساطة نمط التقسيم وبما يسهل ويسرع من عملية توقيعه وتتفيذه وليس بالضرورة الالتزام بالنمط الثطرنجي السائد بالمناطق العشوائية

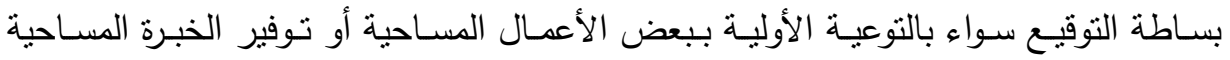
بمقابل مادي مقبول أو رمزي بواء بالئي

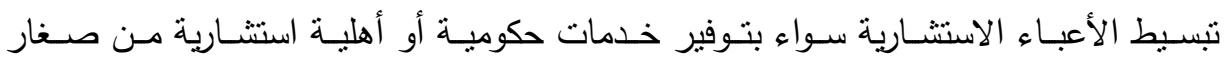
المهندسين المدربين أو بتوفير أنماط معدة سلفاً لتقسيمات الأراضي والتصميم يمكن الحصول لتصول عليها بمقابل رمزي من المحليات. 3-2-2 تبسيط إجراءات الترخيص: وهو ما يساعد على عدم تحايل المنتفعين على الإجراءات ويمكن ذلك من خلال: • اختصار الإجراءات ووضوحها وقصر مدة تتفيذها

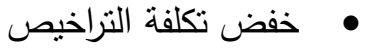
ربط بعض الحوافز بالترخيص متل بعض الخدمات الاستشارية السابق الإثارة إليها 
تعد من العوامل التي تحفز السكان على سرعة تتميـة الموقع السكني استقرار الحيازة وبصورة ملكية خاصة حيث لازالت النمط الثرقي من التفكير يرفض الأنماط الأخرى مثل حق الاتنفاع والملكية المؤقتة. كما تعد بساطة وانخفاض تكلفة توثيق الملكية من العوامل التي تحفز السكان على البناء والاستقرار. 4- الموارد والسمات الاقتصادية بالمناطق العشوائية: 4-1-4 الواقع والسلوكيات الاقتصادية بتلك المناطق: تعد الإثكالية الأكبر في ظاهرة الإسكان العشوائي التباين الكبير بين ما تظهره دراسات الدخل من تدني

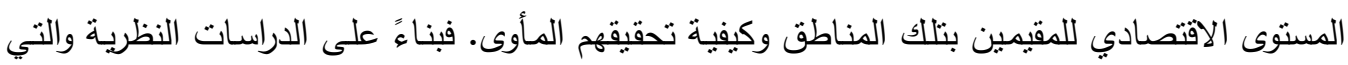
تصنف أغلبها سكان تلك المناطق ضمن شريحة ذويي الدخل المحدود تكون هناك استحالة في تحقيق

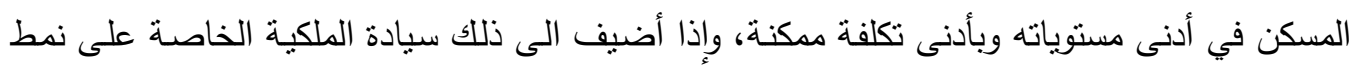

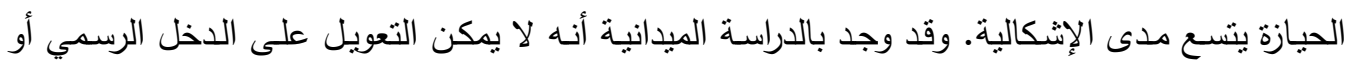

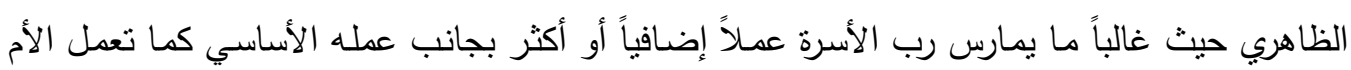

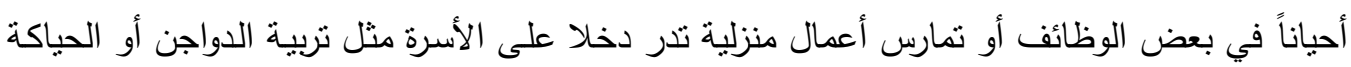

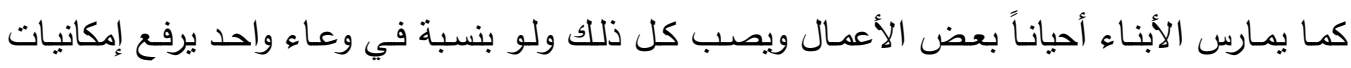

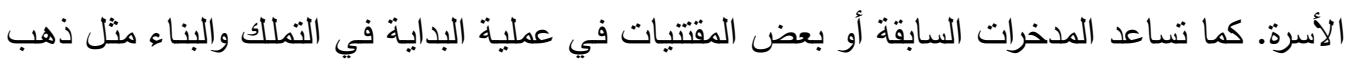

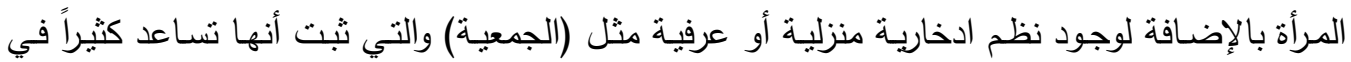
تنمية المدخرات [السفطي,1986]. 4-2 الخبرات المستفادة: 4-2-4 تفعيل الموارد الاقتصادية الكامنة للمعنيين:

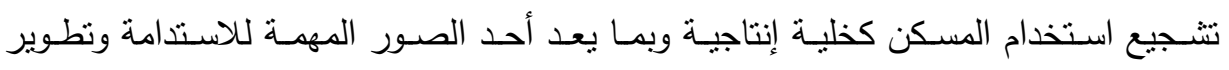
الأنشطة النمطية (منل تربية الدواجن) لتلافي الأضرار الصحية واستحداث أنشطة مبتكرة (مثل

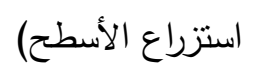

التشجيع وإيجاد البدائل لممارسة أكثر من عمل مثل توفير أعمال لوقت جزئي تيسير القروض للمشروعات المتتاهية الصغر وخاصة للمرأة تيسير فرص العمل للثباب العاطل تيسير فرص العمل للأبناء بمراحل التعليم بمراحل وخاصة في فترات الأجازة

4-2-2-2 تشجيع الادخار دعم وتطوير الوسائل العرفية للادخار مثل ما يسمى "الجمعيات" وتوفير سبل نوثيقها حتى 


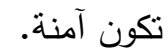

ابتكار أوعية مبتكرة تساعد على الادخار واجتذاب أموال السكان.

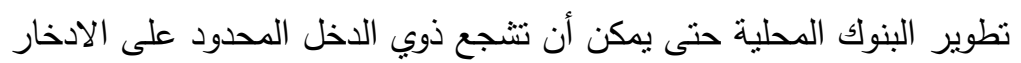

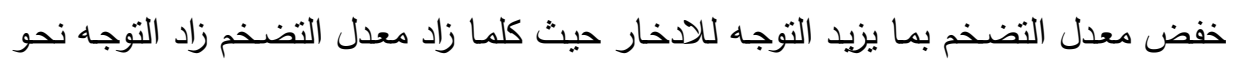

اقتتاء السلع حتى لو لم تكن الحاجة إليها قائمة

5- نمط ومراحل النمو للمستوطنات العشوائية:

5-1 التمويل الأتي والنمو المرحلي

في مناطق الإسكان العشوائي ورغم ما سبق من وجود موارد اقتصادية كامنة ومدخرات لكن ذللك لا ينفي

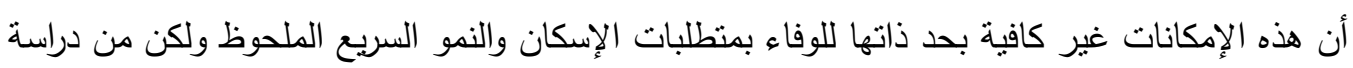

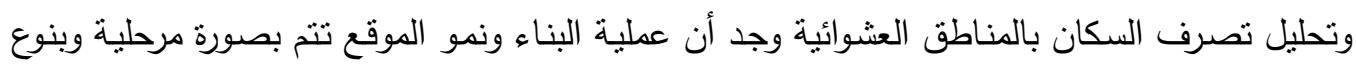

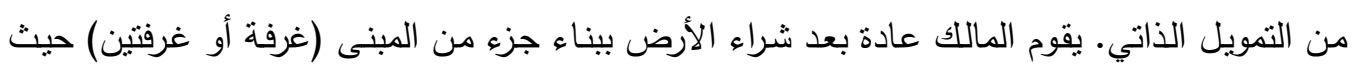

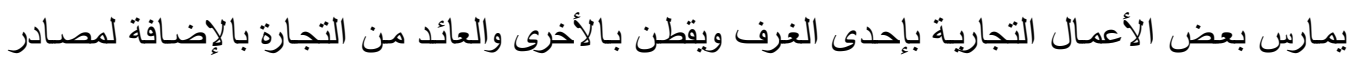

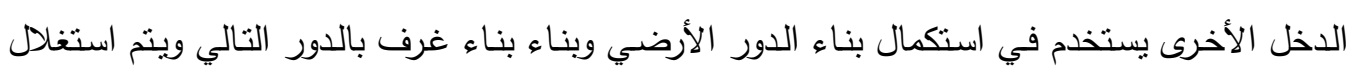
الدور الأرضي تجارياً وتأجير الجزء الباقي واستغلال العائد في استكمال البناء وهكذا.

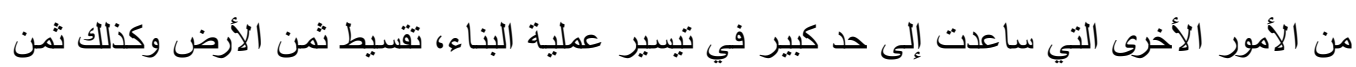

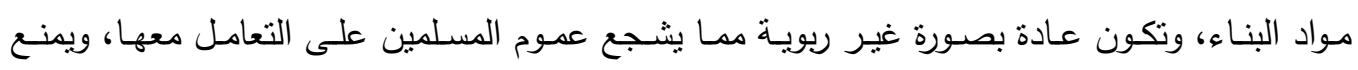
اسنتزاف الموارد الأولية وتوجيهـا للبناء ثم سداد الأقساط من عائد البناء. 5-2 الخبرات المستفادة لاعم المشرعات العمرانية: مما سبق يمكن استنتاج العوامل التالية التي تساعد على نمو المشرعات العمرانية لذوي الدخل المحدود: 5-2-2 النمو المرحلي واستدامة الموارد الاقتصادية:

مرونة استخدام المبنى لأكثر من غرض بل وفي بعض الأحيان إعادة بناء أو تأهيل المبنى

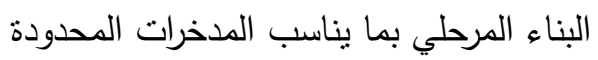
استغلال كل مرحلة من البناء اقتصادياً واستغلال العائد في المراحل التالية من عملية البناء الثرداء

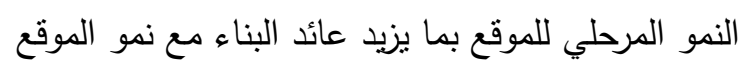
5-2-2 نظام التقسيط بما يحفظ الموارد الأولية: تقسيط ثن الأرض مما يساعد على البدء السريع بعملية البناء. تقسيط ثمن مواد البناء مما بساعد على الاستمرارية. كون التقسيط غبر ربوي يشجع فئات محافظة على الثقسيط. 


\section{5-2-5 أسلوب مساكن النواة كمنهج مناسب لتنمية مشروعات الإسكان:}

من السابق نجد أن السلوك السابق أقرب ما يكون من مشـاريع مسكن النواة وهو ما يدفع إلى تفعيل

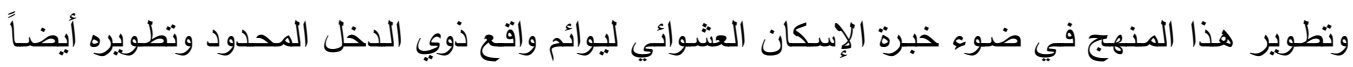
ليوائم شرائح الدخل الأعلى نسبياً.

\section{6 - 6 - جهود السكان بالمناطق العشوائية}

6-1 المشاركة المجتمعية كفاعل أساسي في توفير الخدمات وتحقيق الانتماء

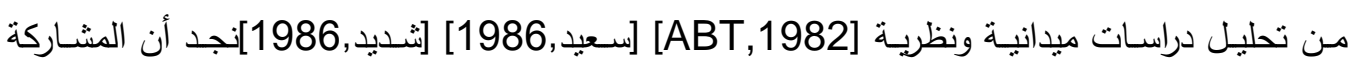

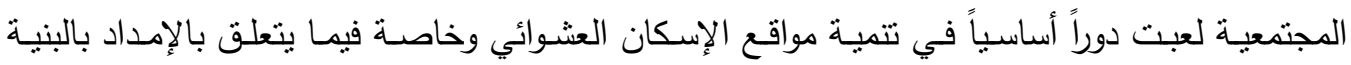
الأساسية والخدمات المجتمعية. ويمكن تصنيف الجهود المجتمعية إلى جهود فردية وجهود جماعية أهلية

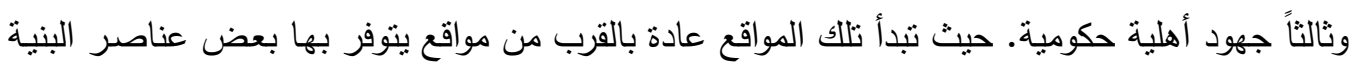

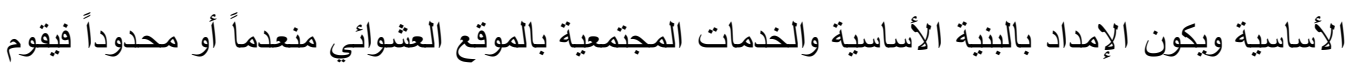
السكان (على سبيل المثال المختصر لا الحصر) بمحاولة توفير العناصر الممكنة من البنية الأساسية

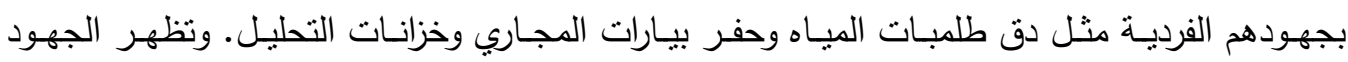

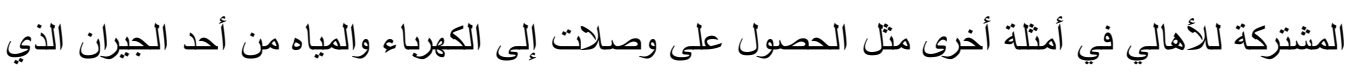

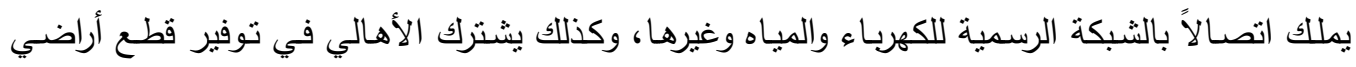

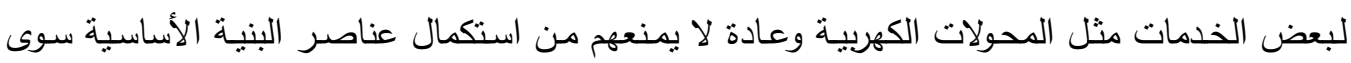

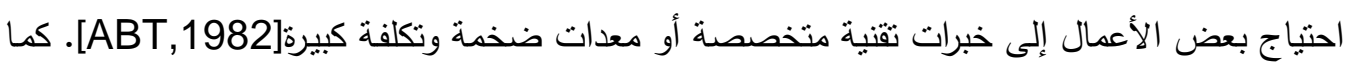
تبرز الثراكة الأهلية الحكومية في أمتلة كقيام السكان بالضغط على التى الجهات الحكومية باستغلال الثقل

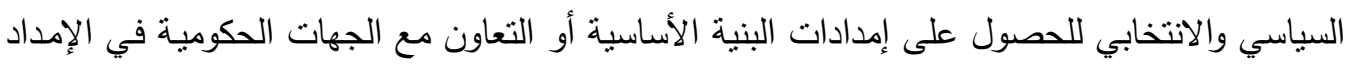

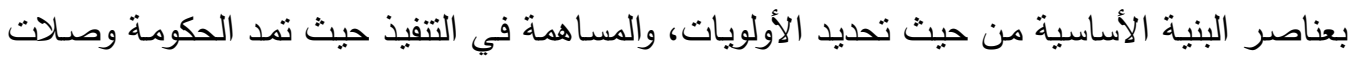
المستوى الأول والثاني من الثبكات ويتحمل السكان الإمداد بشبكات المستوى الثالث.

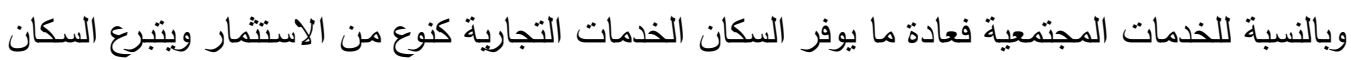

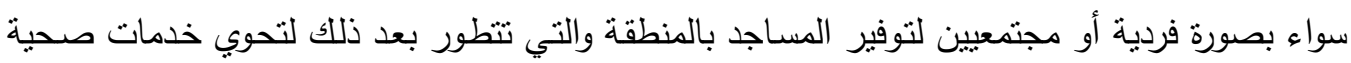




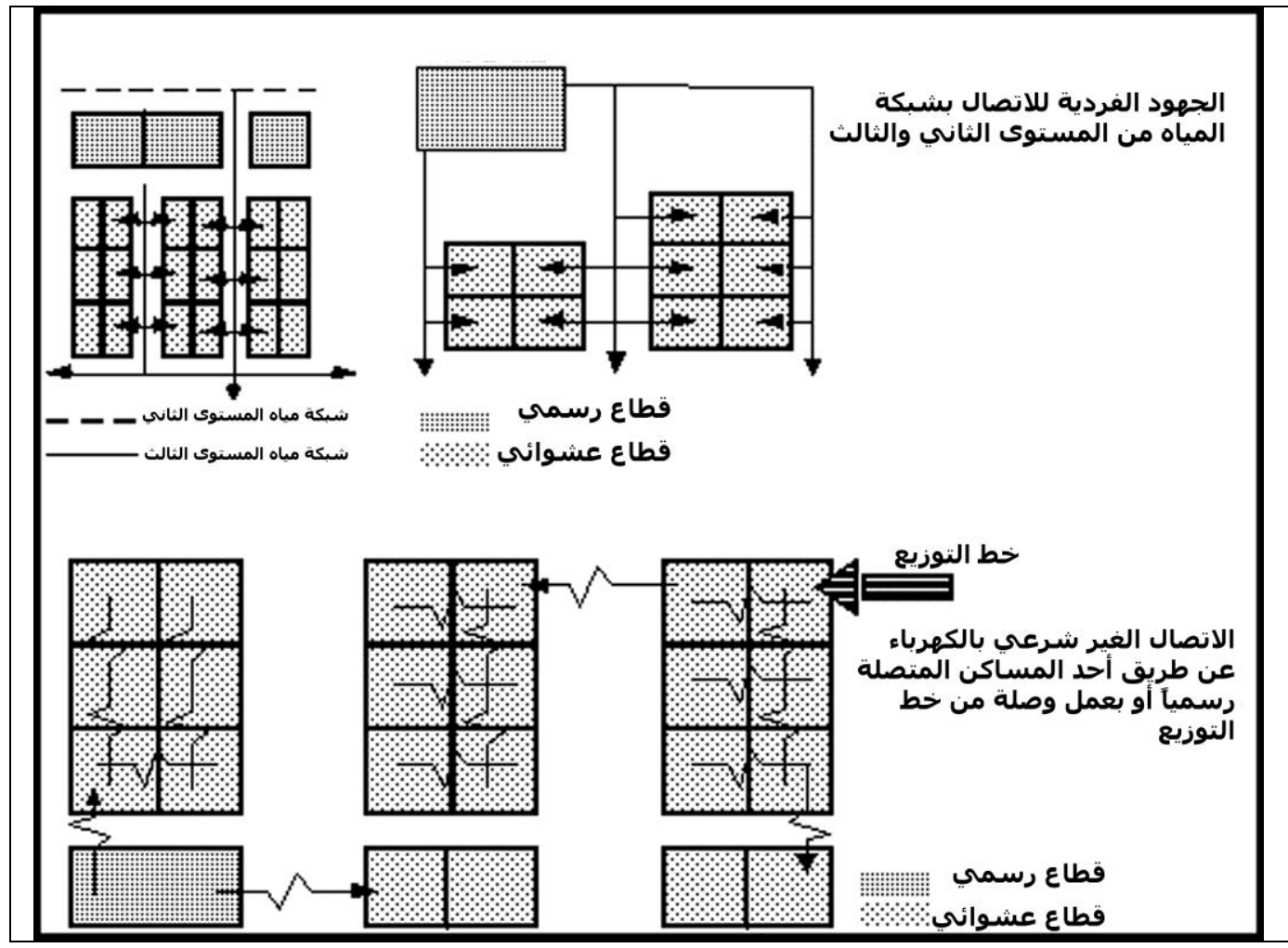

شكل (6) يوضح جهود السكان بالمناطق العشوائية في الاتصال بشبكات المياه والكهرباء عبر المناطق

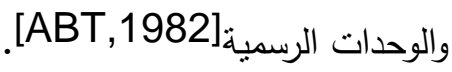

$$
\text { 6-2 الخبرات المستفادة }
$$

مما سبق يمكن الثركيز على الجوانب النالية:

6-2-6 تفعيل المشاركة الشعبية في الإمداد بالبنية الأساسية:

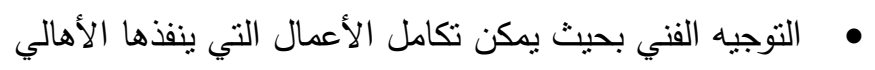

• ابتكار نظم بسيطة للبنية الأساسية يمكن إنجازها مجتمعياً

• • • • • • • • • وضع تصور واستعداد حكومي مسبق لكيفية إدارة مرنة لتتفيذ الأعمال بمشاركة الأهالي.

2-2-6 تفعيل المشاركة الشعبية في الإمداد بالخدمات المجتمعية: • • • تيسير الإجراءات والتراخيص اللازمة لبناء الخدمات العامة.

• تفعيل دور المسجد وعلم قصره على الدور الليني المحلود ليعود مؤسسة اجتماعية تعليمية صحية...إلخ.

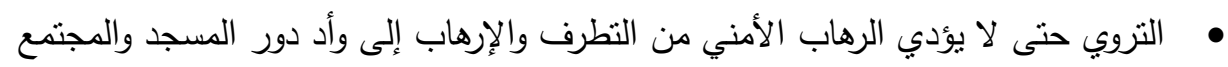


• التوعية الدينية وشمولية الفكر حتى يستوعب العامة أن التبرع لمدرسة أو مستثفي يوازي التبرع

للمسجد أو قد يزيد.

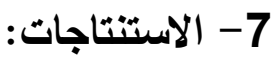

مما سبق أمكن أن نستتنج من تجربة الإسكان العشوائي مجموعة من العوامل والمعايير التي يمكن أن تدفع مشروعات إسكان ذوبي الدخل المحدود وتدفع مشروعات التتمية ككل يمكن إيجازها في:

1-7 توجيه عمليات التنمية العمرانية

حيث يمكن ذلك باستغلال السلبيات وعوامل الطر الموجودة بالمدن القائمة وعدم تتميتها كحوافز سلبية

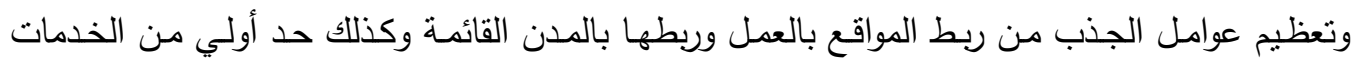

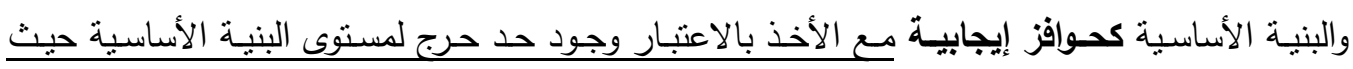

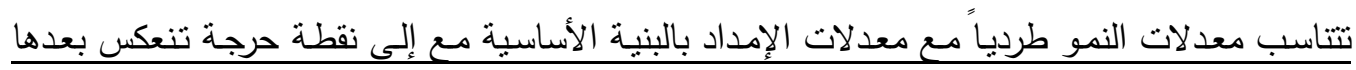

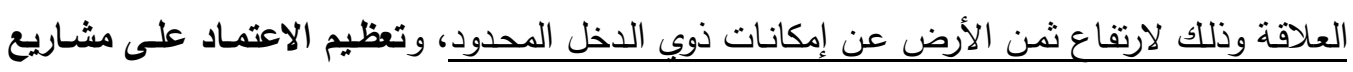

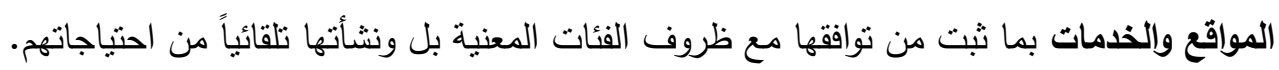

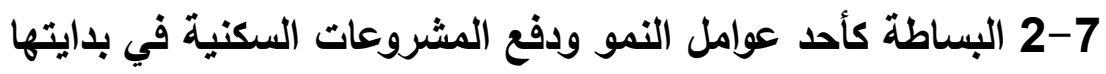
حيث تكون بساطة كل من تقسيم الأراضي وإجراءات الترخيص وتبسيط إجراءات الملكية واستقرارها من العوامل التي تساعد على نمو المشروعات السكنية رغم محدودية الإمكانات.

7-7 استغلال الموارد الاقتصادية الكامنة

عادة ما يكون إلى جانب الدخل الظاهري المتدني إمكانات كامنة تتفاوت بالطبع من حالة إلى أخرى وهو

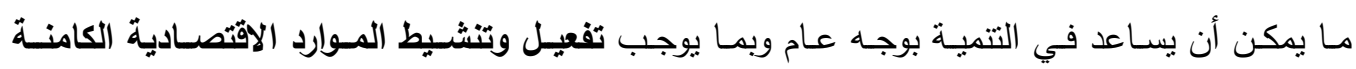

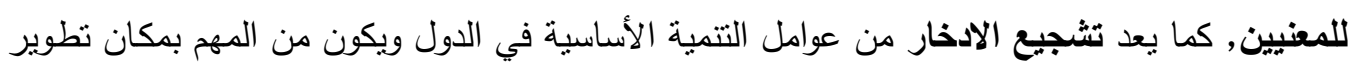

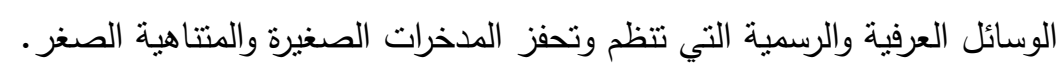
4-7 الاستدامة ورفع كفاءة استغلال الموارد الاقتصادية

يعد النمو المرحلي للمبنى وللموقع، ونظام التقسيط، وتعظيم دور المسكن كخلية إنتاجية، من العوامل

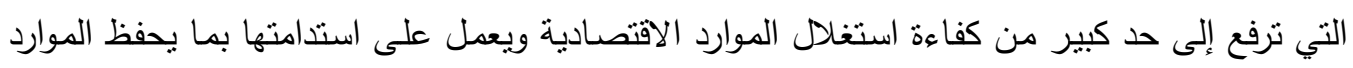
الأولية. ويمكن التركيز على أسلوب مساكن النواة كمنهج مناسب لتفعيل تلك الاستدامة مع تطويره ليشمل الفئات الأعلى دخلاً. كذلك توفير النظم الإسلامية للتقسيط في المجال العقاري بما بشجع الإقبال عليه.

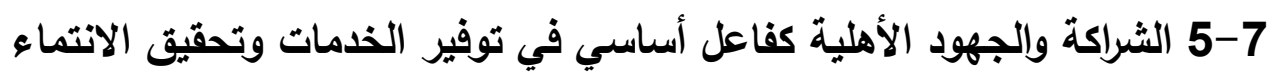

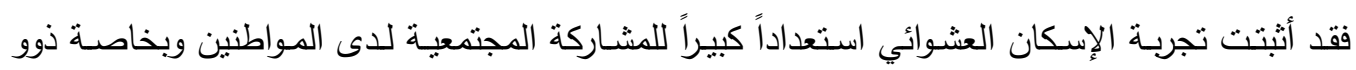

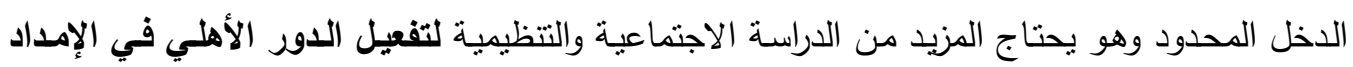


بالبنية الأساسية والمشـاركة في الإمداد بالخدمات المجتمعية وفي مشروعات التتمية عامـة, ويحتاج

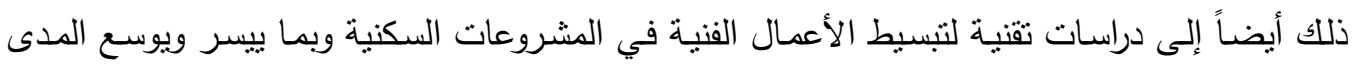
الممكن للمشاركة من غير المحترفين.

\section{8- 8 - 8 - 8لاصة:}

هناك منظومة اعنبارية نشأت مع نشأة المناطق العشوائية وأعطت قوة دفع كبيرة لهذه الظاهرة. من تلك

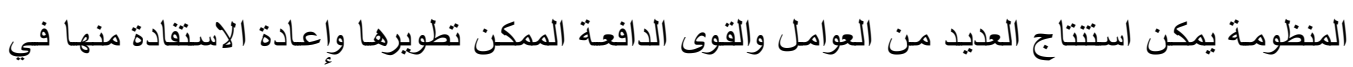
مشـاريع الإسكان وبخاصـة لذوي الدخل المحدود. من أهم تلك العوامل توجيـه التتميـة العمرانية بتفعيل وتوظيف الموجود من عوامل طرد طبيعية في التجمعات الأقدم وعوامل جذب في مناطق الامتداد من

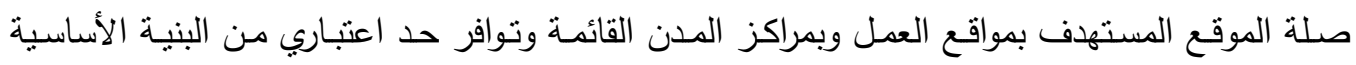
والخدمات (نقطة حرجة) نساعد على انتخاب الفئات المستهدفة، وبساطة عملية تقسيم الأراضي. كذلك الكي

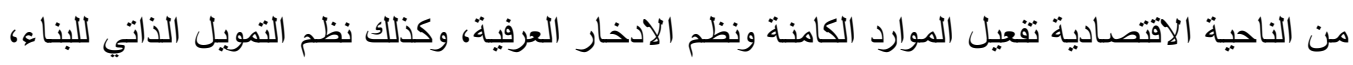

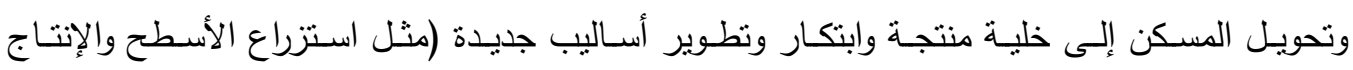
الحيواني) بما يدعم الاستدامة، ونظم التقسيط والقروض الغير ربوية التي نوافق الثريعة يثجع الأهالي

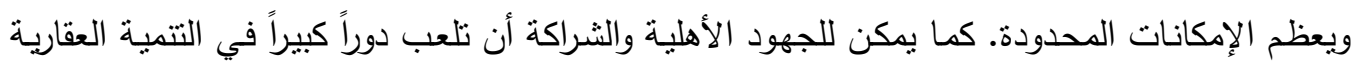

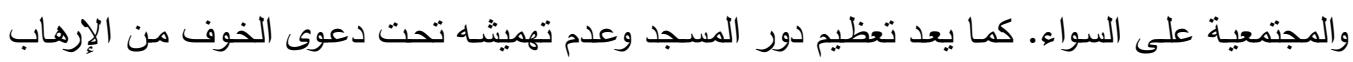

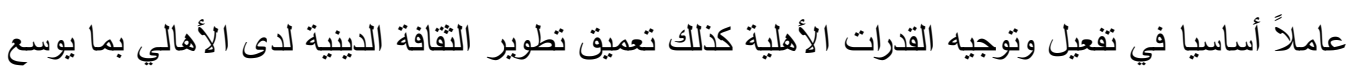

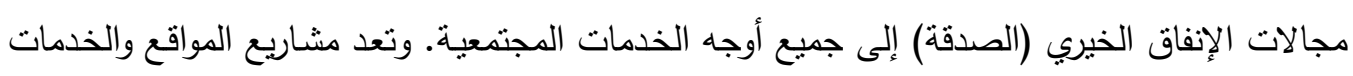

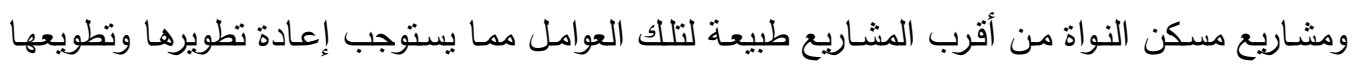
للظروف المستتبطة من الخبرات المستفادة من المناطق العشوائية.

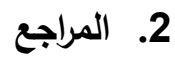

1- برادة, عبد المحسن (أبريل 1986) الجوانب الإيجابية في عمليات النمو العشوائي", مجلة جمعية

$$
\text { المهندسين المصرية, عدد 373, مصر. }
$$

2- الجهاز المركزي للتعبئة العامـة والإحصـاء (1996) "الكتاب الإحصـائي السنوي لجمهوريـة مصر

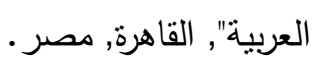

3- سـعيد, صـلاح زكي (مـارس 1986) "الإسـكان العشوائي والإسـكان العـام بالقـاهرة مقارنـة لبعض

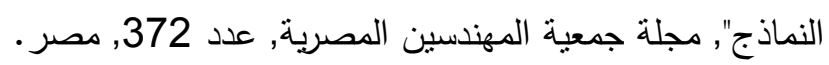

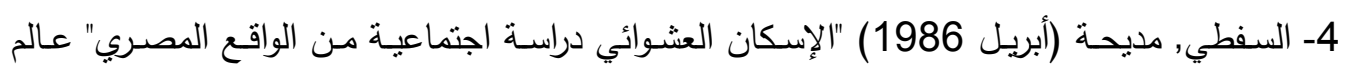
البناء, عدد 43, مصر. 
5- شديد, يحي عثمان (يناير 1986) "بحوث ميدانية مقارنة عن الإسكان بالمناطق العشوائية", المؤتمر

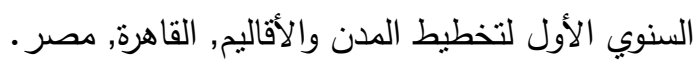

6- عـامر , إسـماعيل عبد العزيـز (مـارس 1986) "الانفجـار السكاني والنمـو العشـوائي للمجنمعـات العمرانية بمصر", مجلة جمعية المهندسين المصرية, عدد 372, مصر •

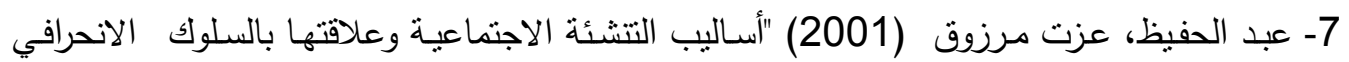
دراسة ميدانية في إحدى المناطق العشوائية بمدينة أسيوط" ماجستير في الآداب

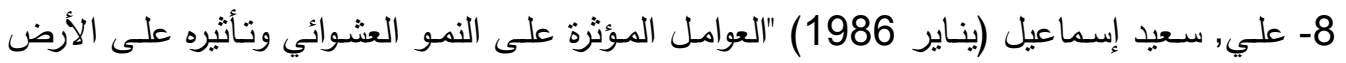

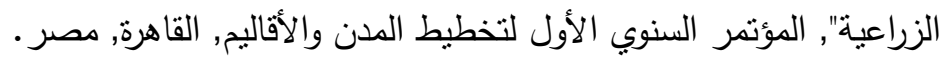

9- عبد, محمد عبد السميع (1988) "مشاريع المواقع والخدمات كمدخل لحل مشكلة إسكان ذوبي الدخل

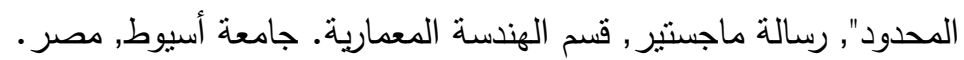

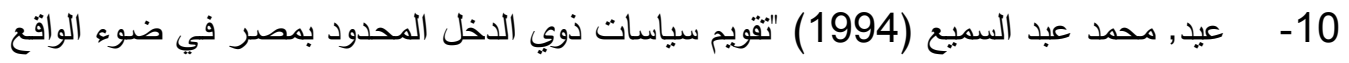

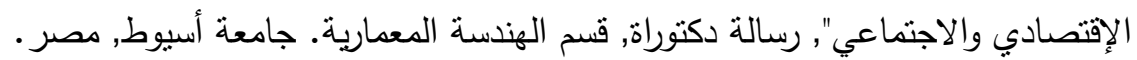

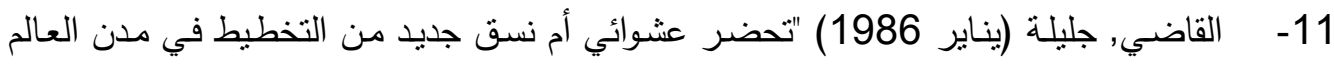

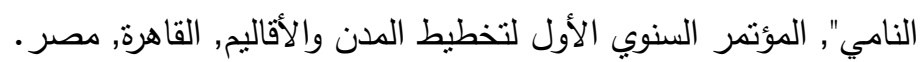

12- Abd-El-Alim, Aymen Eissa (1998) "Proposal Model for Upgrading Informal Housing Areas", Ph.D. thesis, Dept., of Arch., Assiut University, Assiut, Egypt.

13- ABT. Associates INC., (1982) "Informal Housing In Egypt", Dames and Moore, USA. 